\title{
PORTO CORONEL RENATO EM MANCHETE: O LITÍGIO FRONTEIRIÇO ENTRE BRASIL E PARAGUAI NOS PERIÓDICOS DE AMBOS OS PAÍSES
}

\section{PORTO CORONEL RENATO IN STAGE: THE BORDER LITIGATION BETWEEN BRAZIL AND PARAGUAY IN THE PERIODICS OF BOTH COUNTRIES}

Luiz Eduardo Pinto Barros ${ }^{1}$

RESUM0: Nos anos 1960, as relaçóes entre Brasil e Paraguai estavam sendo intensificadas com importantes acordos políticos e econômicos. No entanto, a ocupação militar brasileira numa regiáo de fronteira, em 1965, causou desgaste na dinâmica brasileiro-paraguaia. Manifestaçóes de repúdio ao Brasil foram expostas no Paraguai de diferentes formas, tendo grande espaço na mídia controlada pela ditadura militar de Alfredo Stroessner que soube tirar proveito da situação e explorar o litígio fronteiriço a favor de sua imagem como "defensor dos interesses nacionais". Já no Brasil, sob um regime militar, o assunto teve menor repercussão, mas foi explorado por periódicos brasileiros de maior circulaçáo como interesse nacional, ao mesmo tempo em que houve casos de veículos oposicionistas declarados fizessem do impasse mais um objeto de crítica ao governo Castelo Branco.

Palavras-Chave: 1) Energia 2) Soberania 3) Interesses políticos.

ABSTRACT: In the 1960s, relations between Brazil and Paraguay were being intensified with important political and economic agreements. However, the Brazilian military occupation in a frontier region, in 1965, caused attrition on the Brazilian-Paraguayan dynamics. Manifestations of repudiation of Brazil were exhibited in Paraguay in different ways, with large space in the press media controlled by the military dictatorship of Alfredo Stroessner who knew how to take advantage of the situation and to explore the border litigation in favor of his image as "defender of national interests". In Brazil, under a military regime, the subject had less repercussion, but was explored by Brazilian journals of greater circulation as national interest, while there were cases of declared opposition members made the impasse one more object of criticism to the Castelo Branco government.

Keywords: 1) Energy 2) Sovereignty 3) Political interests.

\section{INTRODUÇÃO}

Este artigo trata de um litígio fronteiriço entre o Brasil e Paraguai na década de 1960 e sua abordagem em periódicos dos dois países que faz parte da dissertação de mestrado intitulada Os Saltos da Discórdia: o impasse diplomático entre Brasil e Paraguai em torno

Doutorando PPGH/UNESP-Franca. E-mail: luizeduardopb@hotmail.com 
das Sete Quedas (1962-1966), publicada em forma de livro em 2013. As divergências entre os dois países tiveram início por conta dos estudos realizados pelo Estado brasileiro na regiáo de Sete Quedas sem consultar o governo paraguaio que ao ter conhecimento do assunto questionou imediatamente as autoridades brasileiras, em 1962, pois defendia o argumento de que a soberania daquela fronteira ainda náo havia sido definida apesar das assinaturas do Tratado de Paz e Limites (1872) e do Tratado Complementar de Limites (1927) por conta de divergências demonstradas pelos paraguaios da Comissão Mista de Fronteira na década de 1930 na caracterização daquela área. Em 1965, quando o Brasil já estava sendo governado por um regime ditatorial, militares brasileiros ocuparam aquela regiáo em Porto Coronel Renato. Tal ocupação causou maiores desentendimentos nas relaçóes entre Brasil e Paraguai que naquele momento estavam intensificando uma aproximação política e econômica iniciada nas décadas anteriores. Em solo paraguaio, manifestaçóes contrárias à ocupação brasileira ganharam repercussão tendo muito impacto na atuação do governo Stroessner, uma ditadura militar desde 1954, em defender os interesses do país.

O assunto repercutiu na imprensa escrita dos dois países, com mais ênfase no Paraguai, que naquele ano celebrava o centenário do início da "Epopeia Nacional", a Guerra da Tríplice Aliança (1864-1870) que teve sequelas no país guarani, mas um grande valor simbólico. O governo Stroessner fez uso da imprensa para alavancar a sua imagem de "defensor dos interesses nacionais", ao mesmo tempo em que angariava apoio, inclusive de membros da oposição exilados no exterior, para garantir o aproveitamento hidro-energético do curso médio do Rio Paraná e adquirir vantagens econômicas. Já no Brasil, manifestações de apoio ao governo foram demonstrados na imprensa escrita, principalmente dentre aqueles que apoiaram o golpe civil-militar de 1964. Mas, dentre os opositores ao regime, como o Última Hora, o "caso Sete Quedas" foi mais um elemento de crítica ao governo Castelo Branco em determinado momento. O desfecho do impasse com a assinatura da Ata das Cataratas, em junho de 1966, teve manifestação favorável em grande parte dos periódicos de ambos os países, mas críticas ao acordo não deixaram de ser publicadas. As publicações referentes ao litígio fronteiriço foram muito utilizadas pelas embaixadas de ambos os Estados para informar seus governos da repercussão do assunto, chegando a um momento em que os chanceleres Juracy Magalhães (Brasil) e Sapeña Pastor (Paraguai) fizeram acusaçóes contra o Estado vizinho alegando utilizar o "caso Sete Quedas" para desviar de assuntos internos.

Inicialmente faço uma breve exposição das relaçóes entre o Brasil e Paraguai desde a chegada de Stroessner ao poder, em 1954, até o momento que o impasse diplomático teve início na década de 1960. Em seguida é exposto o assunto para situar o leitor a fim de compreender a dimensão do “caso Sete Quedas”. Logo serão tratados a repercussão do litígio fronteiriço na imprensa de ambos os países com maiores detalhes concomitante ao processo de trocas de notas entre os dois Estados até a assinatura da Ata das Cataratas. Documento este que serviria de base para a assinatura do Tratado de Itaipu, entre Brasil e Paraguai, em 1973, e daria origem à construção da maior hidrelétrica do mundo até poucos anos atrás. 


\section{OS ANTECEDENTES DAS RELAÇÕES BRASIL-PARAGUAI}

Em maio de 1954, Alfredo Stroessner liderava um golpe de Estado que derrubou Federico Chaves. Três meses depois ele mesmo assumiria o poder para perpetuar por trinta e cinco anos e fazer do seu governo uma das ditaduras mais autoritárias da América Latina. Stroessner era filiado ao partido Colorado que estava à frente do Estado paraguaio desde 1947. Durante este período diversos golpes de Estado ocorreram entre membros do próprio partido e com a chegada de Stroessner certos membros da oposição, como do Partido Liberal e Febrerista acreditavam que a derrubada de Federico Chaves seria a saída definitiva dos Colorados. Porém, Stroessner fez usos de instrumentos para legitimaçáo do poder como: o uso das Forças armadas, a censura à imprensa e o controle da mesma; a aproximaçáo com a Igreja Católica; e o próprio partido Colorado. O presidente paraguaio promoveu várias eleiçóes, com participação exclusiva dos colorados, para demonstrar a "legalidade" de seu governo (MORAES, 1996).

$\mathrm{Na}$ condução da política externa, Stroessner deu continuidade ao processo de aproximação em relaçáo aos Estados Unidos que vinha ocorrendo desde o governo de Estigarribia (1939-1940) quando o Estado norte-americano buscava evitar a aproximação diplomática dos países latino-americanos com os países do Eixo (Alemanha, Itália e Japão). Em 1943, bases estadunidenses foram instaladas em Assunçấo na mesma época que foi iniciada uma Missáo Militar norte-americana. A aproximaçáo com os Estados Unidos, durante o governo Stroessner, estava relacionada a interesses econômicos e, sobretudo, políticos, muito em consequência da conjuntura da Guerra Fria e a aversáo que os colorados tinham em relação ao comunismo representado em grande proporção geopolítica na figura da União Soviética (MORAES, 1996).

No cenário sul-americano, Stroessner manteve uma política pendular em relação aos seus dois grandes vizinhos, Brasil e Argentina. A aproximaçáo com o Estado brasileiro foi resultado de diversos fatores. Um deles foi o fato de as autoridades políticas na Argentina, após a queda de Perón em 1955, demonstrarem insatisfaçáo com o governo de Stroessner. Diversos exilados dos partidos de oposição em solo argentino tramavam realizar um golpe de Estado para derrubar o entáo ditador paraguaio. Ainda sobre a Argentina havia uma questáo importante: desde o início do século XX, quando o Partido Liberal assumiu o poder em meio a uma guerra civil, os liberais eram próximos da Argentina conquistando apoio político das autoridades desta. Outro motivo do entrelaçamento das relaçóes brasileiro-paraguaias foi o histórico de Stroessner antes de ascender à presidência: ele havia participado das missóes de treinamento do exército paraguaio no Rio de Janeiro (MORAES, 1996).

Nos primeiros anos de seu governo, Stroessner conseguiu apoio político e econômico do Estado brasileiro na construção da Ponte da Amizade sobre o Rio Paraná para as exportaçôes e importaçóes do Paraguai sendo um "segundo pulmão" ao país que era muito dependente do porto de Buenos Aires. Também foram aprovados projetos para que o Brasil custeasse a construção de trechos necessários para conectar as estradas paraguaias ao porto de Paranaguá. Neste sentido, Juscelino Kubitschek se encontrou com Stroessner, em 1956, para: 
realizar o ato simbólico de colocar a pedra fundamental no local onde seria construída a ponte e para firmar acordo sobre a construção de uma rodovia que unisse Concepción e Pedro Juan Caballero cidades localizadas no centro-norte do Paraguai" (AMARAL E SILVA, 2006, p. 60).

Em 1959, após uma tentativa fracassada de Golpe de Estado contra o governo Stroessner, Horácio Lafer, Ministro de Relações Exteriores do Brasil, foi enviado a Assunção para demonstrar apoio ao chefe-de-Estado paraguaio. No mesmo ano, o Paraguai concedeu porto franco ao Brasil em Encarnación. Além disso, foi entregue o relatório final realizado pela Comissão Mista responsável por viabilizar a estrada entre Concepción e Pedro Juan Caballero (AMARAL E SILVA, 2006). Já em 1960, o chanceler brasileiro retornou a Assunção para assinar três projetos, sendo um a construção da citada rodovia entre Ponta Porã e Concepción, o desenvolvimento dos trabalhos na Ponte da Amizade sobre o Rio Paraná e um Tratado para Revisão de Textos na área da educação. Neste último caso, seria uma maneira de amenizar o histórico conflito bélico entre os dois países na segunda metade do século XIX.

\section{O LITÍGIO FRONTEIRIÇO}

No decorrer da década de 1950, durante o governo de Juscelino Kubitschek (19561961), o Estado brasileiro estava desenvolvendo estudos para saber do potencial hidroenergético do Rio Paraná, na região das Sete Quedas. O objetivo era atender à demanda energética industrial do país em meio ao seu programa de governo desenvolvimentista do Plano de Metas. A região Centro-Sul passava por um momento de extrema necessidade energética. A capital mineira, Belo Horizonte, por exemplo, em diversos momentos passou por um racionamento de energia no ano de 1959 (LEITE, 1988, p. 125). Os estudos realizados ocorreriam na fronteira com o Paraguai e, ao que tudo indica, o país vizinho não havia sido consultado.

Já no governo Jânio Quadros (1961), o então presidente defendia o projeto de serem construídas duas usinas no curso médio do Rio Paraná, sendo:

uma em Prainha, que poderia gerar de 1 até 4,5 milhóes de KWA, e outra em Arroio Guazu, a trinta quilômetros de Sete Quedas com potencial para gerar 15 milhóes de KWA, com energia suficiente para vender para o Paraguai e a Argentina caso eles assim o desejassem (LEITE, 1988, pp. 72-73).

O então presidente pediu ao seu ministro de Minas e Energia, João Agripino, para que desenvolvesse mais estudos para saber do real potencial energético da referida região. Mas no início de 1962, um artigo do Jornal do Brasil que tratava sobre os estudos hídricos chamou a atenção da embaixada paraguaia que imediatamente informou seu governo. No mês de fevereiro o embaixador paraguaio, Raul Peña, ao escrever o referido documento, chamou a atenção do governo de seu país informando que os estudos brasileiros visando ao aproveitamento hídrico das Sete Quedas lesionavam os direitos paraguaios referentes à soberania daquela fronteira (PARAGUAI, 1962a).

Pouco tempo depois o governo paraguaio chamou a atenção do Estado brasileiro em relação ao assunto. Em março de 1962, o chanceler Raul Sapeña Pastor enviou uma nota 
questionando as atividades brasileiras em Sete Quedas alegando que até aquele momento a soberania de Sete Quedas não estava definida e por isso tais estudos não poderiam ser realizados sem que houvesse negociação com as autoridades paraguaias:

En el Diario "Jornal do Brasil” correspondiente al día 13 de febrero de 1962, bajo el título "Ministro das Minas nomeia Ferraz para saber como vai aproveitar Sete Quedas", fue publicada la noticia procedente de Brasília que el Ministro de Minas y Energia Sr. Gabriel Passos, autorizado por el Consejo de Ministros, habría contratado los servicios técnicos del Sr. Marcondes Ferraz para confeccionar um relatorio preliminar sobre el aprovechamento integral de "Sete Quedas" en el Rio Paraná. El mismo artículo enumera minuciosamente las investigaçôes que será n emprendidas, y el objeto de los proyetos que serán confeccionados.

La República del Paraguay, y los Estados Unidos del Brasil son naciones ribereńas con respecto al accidente acuático natural que se llama "Salto del Guairá" o "Sete Quedas", o "Salto Grande de las Siete Caídas”, que se forma cuando la Cordillera de Mbaracayú intercepta al Rio Paraná, originando um gran embalse y numerosas caídas de água que se encuentran dentro de mismo accidente.

El domínio que las Repúblicas del Paraguay y los Estados Unidos del Brasil tienen sobre el conjunto de ese acidente natural conocido como "Salto del Guairá" o "Sete Quedas" o "Salto Grande de las Siete Caídas" recién quedará delimitado dentro del mismo cuando estén concluídas y aprobadas las operaciones de demarcación de limites y caracterización de fronteras que actualmente realiza la Comisión Mixta de Limites y Caracterizacíon de Frontera ParaguayBrasil. Esas operaciones de demarcación de lá línea divisoria por la cumbre de la Sierra del Mbaracayú viniendo de Oeste a Este, han llegado ya a 20 kilómetros del Salto del Guairá.

Mi Gobierno considera que, antes de que dicha demarcación de limites y caracterización de fronteras quede concluída, ninguno de los dos Gobiernos, ni el de Estados Unidos del Brasil ni el de la República del Paraguay podría proponerse unilateralmente el aprovechamiento integral de la energía hidráulica del Salto del Guairá. (PARAGUAI, 1962b)

No momento em que o Estado paraguaio questionava o Brasil sobre os estudos naquela fronteira as relaçóes diplomáticas entre ambos estava em processo de avanço iniciado nas décadas anteriores. Tendo em vista que o Brasil era uma alternativa ao Paraguai para diminuir sua influência em relação à Argentina, o governo Stroessner enfatizou que não queria causar maiores atritos sobre a questáo Sete Quedas e prejudicar os avanços realizados nas últimas décadas em relação ao Estado brasileiro. No entanto, deixou claro que não abriria mão de seus direitos sobre a região:

El propósito de esta nota no es iniciar prematuramente una polémica extemporánea sobre el dominio del Salto del Guairá, sino expresar al Gobierno de los Estados Unidos del Brasil, por el digno conducto de Vuestra Excelencia, que la República del Paraguay, basada en títulos seculares y Tratados vigentes con el Brasil, considera que su dominio territorial y fluvial se extiende sobre el Salto del Guairá o Salto Grande de las Siete Caídas en la medida que será determinada por los resultados de la determinación y caracterización de la frontera, y que en consecuencia, de ser cierta la noticia mencionada bajo el numeral uno de esta nota, ella trasuntaría una medida gubernativa adoptada con lesión de los derechos del Paraguay, cuya vigencia no podría ser mantenida sin deterioro de las cordialísimas y fraternas relaciones que unen a nuestros Pueblos y Gobiernos (PARAGUAI, 1962b).

A resposta brasileira ocorreria meses depois e demonstra a preocupação do Estado em manter boas relaçóes com o Paraguai levando em conta todos os elementos já mencionados anteriormente. $\mathrm{Na}$ ocasião João Goulart era o presidente do Brasil e daria brechas para o 
país vizinho usufruir em conjunto os recursos hídricos de Sete Quedas. Porém, não abria mão de afirmar que a referida regiáo era de soberania brasileira como é possível perceber no documento enviado pelo chanceler Afonso Arinos de Melo Franco ao Estado paraguaio:

A posse que o Brasil tem sobre o conjunto do Salto das Sete Quedas ficou definitivamente reconhecida e estabelecida, de acordo com os trabalhos da Comissão Mista Brasileiro-Paraguaia encarregada de demarcar os limites determinados pelo Tratado de 09 de janeiro de 1872, reunida entre 1872 e 1874 . Essa delimitação, claramente definida e aprovada nas Atas da $11 .^{\mathrm{a}}, 12 .^{\mathrm{a}}$ e $16 .^{\mathrm{a}}$ Conferência da Comissão Mista, foi traçada nas cartas originais (parciais e gerais), levantadas e assinadas pelos Comissários dos dois países; firmadas, do lado paraguaio, pelo Comissário D. Domingo A. Ortiz e seu secretário D. Espinoza, em Assunção, a 20 de outubro de 1874, encontram-se arquivadas no Itamaraty, podendo ser confrontadas a todo momento. Dirime qualquer dúvida a esse respeito a Ata da $18 .^{a}$ e última Conferência da Comissão Mista de 1872-1874, subscrita, também em Assunção, a 24 de outubro de 1874. Tudo assegurado - categórica e finalmente — nos termos do preâmbulo do TRATADO DE LIMITES, COMPLEMENTAR AO DE 1872, assinado no Rio de Janeiro aos 21 dias do mês de maio de 1927. Por isso mesmo, o "Protocolo de Instruçóes para a demarcação da fronteira Brasil-Paraguai", de 09 de maio de 1930 - que, decorre do "Tratado de Limites, complementar ao de 1872", instituiu a "Comissão Mista de Limites e de Caracterização de Fronteira Brasil-Paraguai”, atualmente vigente - no seu art. $10 .^{\circ}$, determinou, apenas, a restauração dos antigos marcos e intercalação de novos entre os já existentes, nas terras altas da fronteira (PARAGUAI, 1962b).

Para entender os argumentos que estavam em jogo é necessário fazer uma análise histórica do processo de demarcação da regiấo de Sete Quedas. Em 1872, Brasil e Paraguai firmavam o Tratado de Paz e Limites que definia a fronteira física de ambos após o desfecho da Guerra da Tríplice Aliança (1864-1870) que envolveu Brasil, Argentina e Uruguai contra o Paraguai do qual este sai derrotado com várias sequelas políticas, econômicas e sociais. Entre 1872 e 1874, a Comissão Mista brasileiro-paraguaia desenvolveu seus trabalhos de demarcação onde deveriam ser colocados os marcos de acordo com o Tratado. Um trecho do primeiro artigo deste aponta que a fronteira entre os dois países está separada pelo leito do Rio Paraná "desde onde começam as possessóes brasileiras na embocadura do Iguaçu até Salto Grande de las Siete Caídas do mesmo Rio Paraná. Do Salto Grande de las Siete Caídas à linha demarcatória continua pela Sierra de Mbaracayú até o ponto em que esta termina". Neste sentido, vale ressaltar que "as fronteiras são estabelecidas tendo por ponto de referência preferencialmente os acidentes geográficos como rios, lagos e montanhas" (BETIOL, 1983, p.15). E no caso destas ou morros, a fronteira é definida pela ligação dos pontos mais altos.

No caso da fronteira Brasil-Paraguai na região de Sete Quedas, o cume da Serra de Maracaju é o ponto de referência. $\mathrm{O}$ tratado define que a fronteira segue pelo leito do Rio Paraná até o Salto das Sete Quedas e daí segue pela Serra de Maracaju. O problema, porém, é que esta serra possui, naquela regiáo, dois ramos, um ao norte e outro ao sul, os quais convergem para as Sete Quedas. Em outubro de 1874, quando foi realizada a 16. ${ }^{\text {a }}$ conferência da comissão brasileiro-paraguaia de limites, a fronteira foi definida pelo ramo sul, pelo qual o cume da serra de Maracaju chega até a quinta queda, considerada entáo como o ponto mais alto. 
Em 1927 foi o Tratado Complementar de Limites com o objetivo de terminar a caracterização da fronteira onde marco não foram colocados. $\mathrm{Na}$ década de 1930 uma comissão mista foi formada e deu continuidade nos trabalhos. Porém, na região de Sete Quedas os paraguaios da comissão apresentaram dúvidas sobre o ponto mais alto acreditando que a primeira queda seria o referencial mais elevado. Com isso, as Sete Quedas seriam de soberania paraguaia e por isso não lavraram as atas. Segundo uma nota enviada pelo embaixador brasileiro em Assunção, Jaime Gomes, em outubro de 1965, os trabalhos de caracterização das Sete Quedas haviam sido paralisados em 1938. Neste momento "os trabalhos da comissão mista foram suspensos, tão somente porque os comissários paraguaios não quiseram lavrar os termos de dezenove marcos já construídos, nem, tampouco concordaram com a construção de outros doze marcos já previstos” (BRASIL, 1965).

As relações entre ambas as nações estavam num momento sólido e Sete Quedas parecia ser mais um motivo de entendimento entre os dois países. O governo brasileiro não abria mão de sua soberania sobre a referida região, mas possibilitava ao Paraguai o benefício de usufruir do seu potencial hídrico. Os dois países pediam apoio de um ao outro em diversos temas internacionais, demonstrando como a diplomacia brasileiro-paraguaia avançava desde as décadas anteriores. Podemos citar como exemplos o pedido do governo paraguaio junto ao Estado brasileiro para apoiar a cidade de Assunção, no sentido que esta fosse no ano de 1965 a sede da Assembleia do Banco Interamericano de Desenvolvimento ${ }^{2}$, e também o pedido feito pelo governo João Goulart ao de Stroessner para que o Paraguai apoiasse o Brasil na sua candidatura como membro do Conselho Administrativo da OIT (Organização Internacional do Trabalho) (BRASIL, 1963).

Do lado paraguaio, o aproveitamento hídrico de Sete Quedas não seria apenas uma oferta para suprir a demanda interna de energia para impulsionar o desenvolvimento, mas também um trunfo no cenário internacional, pois aumentaria progressivamente seus laços com o Brasil e diminuiria a dependência em relação à Argentina, além de ser futuramente sócio da potencialmente maior usina hidrelétrica no mundo. Para Stroessner, que no mesmo ano de 1963 se reelegeu de forma fraudulenta (ÚLTIMA HORA, 1963), além de consolidar cada vez mais sua força dentro do partido Colorado e ter esmagado a oposiçáo política, da qual muitos integrantes estavam exilados na Argentina e no Uruguai, sua imagem perante o público paraguaio seria de um "defensor da nação". Ou seja, mais um instrumento para fortalecer seu poder como chefe de Estado do Paraguai.

Já em relação ao Brasil, a construção de uma usina que aproveitasse o potencial energético de Sete Quedas era uma necessidade. O país tinha urgência em suprir sua demanda energética tão necessária ao desenvolvimento econômico. Negar ao Paraguai o direito de usufruir do potencial hídrico daquela região não apenas geraria uma terrível crise diplomática entre os dois países, ameaçando todas as tentativas de aproximação desde a década de 1940, como também ameaçaria a construção da usina. É provável

2 Ofício do Ministério de Relaçôes Exteriores do Paraguai para o Itamaraty de 20 de dezembro de 1963 - M.R.B $n^{\circ} 151$. 
que as boas relações entre os dois países, mas principalmente os interesses em comum sobre o potencial de Sete Quedas, fizeram Stroessner visitar João Goulart, na fazenda Três Marias em Mato Grosso. O encontro ocorreu no dia 19 de janeiro de 1964 e teve grande repercussão na imprensa brasileira. Em uma entrevista coletiva na Granja do Torto, em Brasília, Jango declarou: "Tenho a maior satisfação em anunciar que, com a colaboração do Paraguai, construiremos a maior usina hidrelétrica do mundo”.

Meses depois daquele encontro João Goulart sofreria um golpe civil-militar e um regime ditatorial estava sendo implantado no Brasil. Em meado de abril de 1964, Castelo Branco assumia a presidência do Brasil e manteria as relações de aproximaçáo com o Paraguai realizando vários acordos. Em março de 1965 a Ponte da Amizade foi inaugurada, ligando Foz do Iguaçu a Puerto Presidente Stroessner (atual Ciudad del Este) e tornou-se um grande marco nas relaçóes entre ambas as naçóes. A imprensa brasileira na ocasiáo deu grande notoriedade ao fato como o jornal $O$ Globo, que recebeu uma visita do embaixador paraguaio no Rio de Janeiro, Raul Peña, fazendo questáo de cumprimentar o diretor chefe do referido periódico, Roberto Marinho, pelo destaque dado à inauguração da Ponte da Amizade.

Mas o litígio fronteiriço ganharia um novo capítulo meses depois daquela inauguração simbólica. Em de junho do ano de 1965, o governo brasileiro, através de um pequeno contingente de soldados pertencentes à Quinta Companhia de Fronteira, sediada na cidade de Guaíra, localizada no oeste do estado do Paraná, ocupou uma pequena faixa de fronteira denominada Porto Coronel Renato (MENEZES, 1987). E é provável que esta ocupação tenha tido como principal objetivo garantir a soberania brasileira naquela regiáo. Soberania que náo levava em conta apenas uma defesa territorial de Sete Quedas, mas o potencial econômico da mesma.

Em 1965 os paraguaios celebravam o centenário da Epopeia Nacional, o início da Guerra da Tríplice Aliança. No senso comum, o Brasil representava uma "mancha" na história do Paraguai devido a este conflito bélico, apesar dos esforços de aproximação entre ambas as naçôes nas décadas anteriores incluindo a revisão de textos didáticos que representavam o Brasil como um "vilão" na história diplomática do país guarani (MORAES, 1996). A ocupação militar em Porto Coronel Renato esquentou os ânimos de diversos segmentos da sociedade paraguaia possibilitando que novos elementos surgissem para enriquecer a identidade nacional perante a polêmica atitude brasileira. Aos poucos, estava sendo formado um vínculo patriótico, independente de divergências internas, em prol de dado interesse comum: os direitos sobre Sete Quedas. 
Figura 1: Mapa da área em litígio que demonstra onde estavam localizados os militares brasileiros ${ }^{3}$

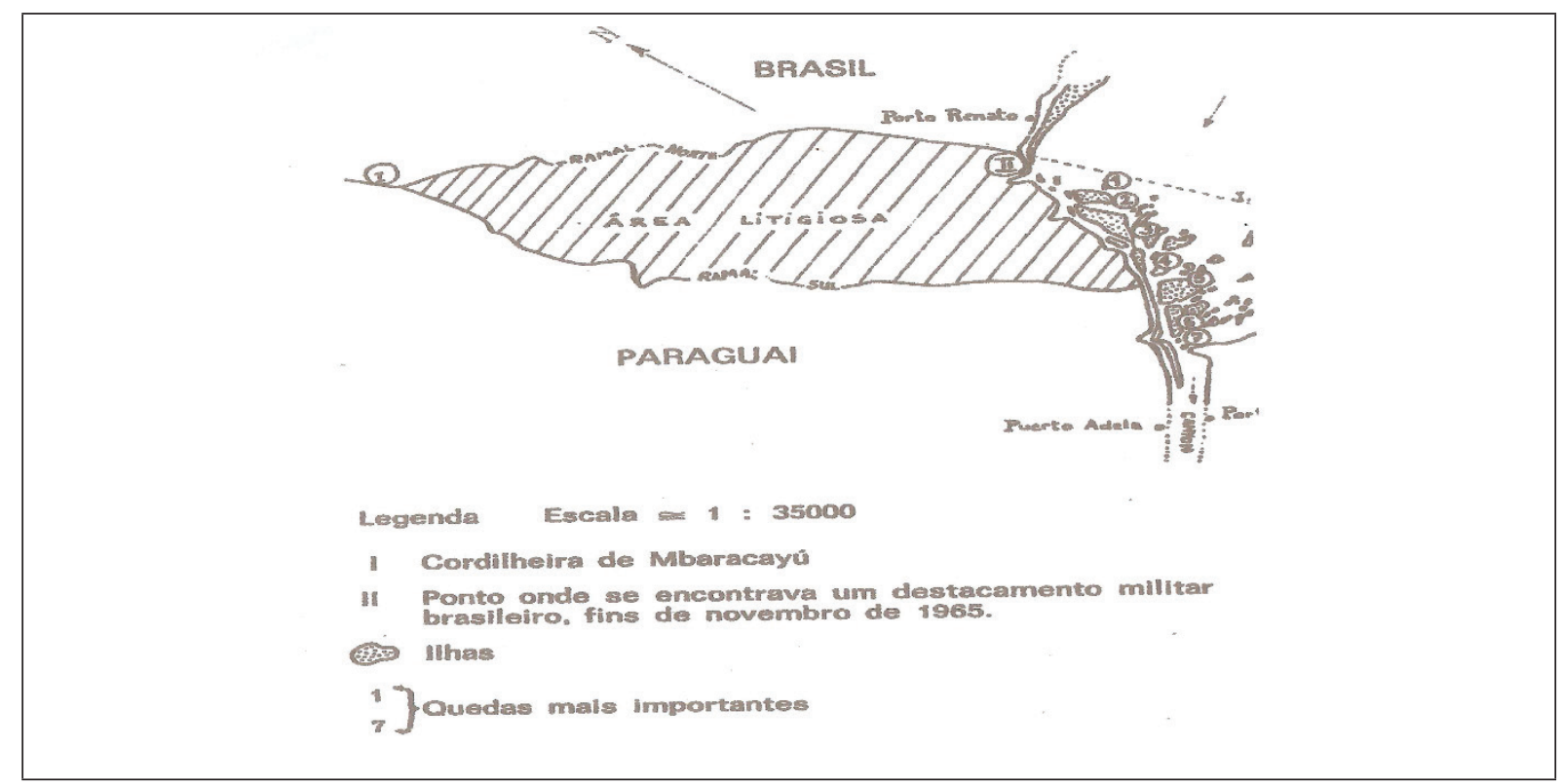

Fonte: CAUBET, 1989, p.14.

Com a repercussão em solo guarani, o governo paraguaio enviou uma nota ao Estado brasileiro questionando aquela ocupaçáo. A resposta viria em outubro de 1965, por meio de uma nota assinada por Souza Gomes, embaixador brasileiro no país, reafirmando os argumentos utilizados pelo governo brasileiro ao responder o questionamento paraguaio três anos antes a respeito dos estudos de potencial hídrico na região das Sete Quedas. Souza Gomes transcreveu trechos das atas assinadas pela comissáo mista de fronteira após a execução de seus trabalhos na década de 1930. Isto porque, como já foi visto, em 1927 foi assinado o Tratado Complementar de Limites que tinha como um dos principais objetivos recolocar marcos nos locais onde os antigos estavam destruídos, além de colocar novos onde não haviam sido colocados.

Mas no conteúdo do documento que foi escrito pelo embaixador Souza Gomes, apresentando o ponto de vista do governo brasileiro, os mais importantes para esta pesquisa foram os que ele transcreveu das atas da $16 .^{\mathrm{a}}$, $17 .^{\mathrm{a}}$ e $18 .^{\mathrm{a}}$ conferências assinadas em 1874 pela comissão mista de fronteira brasileiro-paraguaia. Isto porque, estas são de fundamental importância para compreender o posicionamento do Brasil. Na $16 .{ }^{a}$ conferência, de 19 de outubro de 1974 , foi apresentada a planta da serra de Maracaju e que havia sido assinada pela comissão mista de fronteira. A respeito desta, assim está escrito:

3 A presente figura é originalmente da obra Los Derechos del Paraguay sobre los Saltos del Guairá de Efrain Cardoso e foi citada por Christian Caubet no livro As grandes manobras de Itaipu: energia, diplomacia e direito na Bacia do Prata. 
Esta linha traçada pelo mais alto da serra, parte do marco colocado junto a vertente principal do Igatemi [...] e chega ao marco colocado nas vertentes do Ibicuhy [...]. Do marco do Ibicuhy

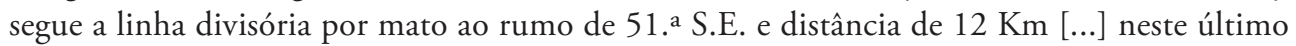
rumo chega a 5. a e mais importante das Sete Quedas, que são formadas pelo encontro da serra com o Rio Paraná, havendo em frente uma pequena ilha (BRASIL, 1965).

A planta da fronteira entre Brasil e Paraguai pelo Rio Paraná, por sua vez, foi apresentada e assinada pela comissão mista na $17 .{ }^{\text {a }}$ conferência, realizada em 20 de outubro de 1874. Já quatro dias depois foi assinada a planta de toda a fronteira entre os dois países na $18 .^{\text {a }}$ e última conferência. A comissão mista de fronteira brasileiro-paraguaia somente se reuniria novamente após a assinatura do Protocolo de Instruçóes, ocorrida em 1930, para dar sequência ao processo de colocação e recolocaçáo de marcos.(BRASIL, op. cit.)

No final de 1965, em resposta à nota brasileira, o ministro de Relaçóes Exteriores, Raul Sapeńa Pastor, enviou um extenso documento no qual recusava os argumentos do governo brasileiro. $\mathrm{O}$ entáo chanceler paraguaio insistia em afirmar que, apesar da assinatura dos tratados de 1872 e 1927 , “existia uma pequena faixa de terra de vinte quilômetros entre o ponto 341/IV e o chamado Salto de Guaíra que até aquele momento não havia sido demarcada". Ademais, acrescentou que como consequência "de uma guerra de extermínio”, na qual o Paraguai foi derrotado na Guerra da Tríplice Aliança, os paraguaios estiveram à mercê do Tratado de Paz e Limites, em 1872 (ÚLTIMA HORA, 1966). E além destas ponderaçóes, sugeriu soluçóes para que o problema fosse resolvido fazendo a seguinte explanação:

a) Que el gobierno de los Estados Unidos del Brasil retire de la zona no demarcada aún (un trecho de 20 kilómetros entre el hito 341 y los Saltos del Guairá) sus fuerzas militares de ocupación, a objeto a ser posible la solución pacífica del diferendo de demarcación.

b) Que la Comisíon Mixta de Límites y Caracterización de la Frontera prosiga normalmente sus trabajos, para cuyo objeto el Gobierno del Brasil dispondrá la concurrencia de su Delegación a la 26ta. Conferencia de la Comisión Mixta, convocada para reunirse en Asunción, en una fecha que se fijará de nuevo por acuerdo de ambos Gobiernos.

c) Que em caso de desacuerdo entre los Gobiernos del Paraguay y del Brasil en el seno de su Comisión Mixta, ambos Gobiernos recurran a todos los medios de solución pacífica de los conflitos internacionales, comenzando por negociaciones directas (PARAGUAI, 1966).

Em síntese, a nota demonstra que o documento enviando pelo governo brasileiro em outubro de 1965 náo convenceu o Estado paraguaio que náo abria máo de defender seus direitos na região de Sete Quedas. E levando em consideração os interesses geopolíticos que aproximavam ambos os Estados o governo paraguaio acreditava que o impasse diplomático seria solucionado de forma diplomática. 


\section{0 "CASO SETE QUEDAS" NOS PERIÓDICOS DE AMBAS AS NAÇÕES}

Segundo o pesquisador José Carlos Avelar, o que uniu o modernismo e o Cinema Novo brasileiro pode ser pensado pelo sentimento da vontade de inventar, de discutir o brasileiro, isto é, na vontade de inventar um instrumental capaz de nos revelar melhor para nós mesmos, pois:

Nos anos de 1965 e 1966, Brasil e Paraguai estavam sendo governados por militares. Em solo brasileiro uma ditadura ganhava forma e viria a se consolidar com o Ato Institucional n. ${ }^{\circ} 5$ em 1968. Em território paraguaio, um regime ditatorial já estava consolidado. As relaçóes diplomáticas entre ambos eram estáveis e diversos projetos estavam sendo colocados em prática como a ligação rodoviária entre Assunção e o Atlântico atravessando o território brasileiro, diminuindo a dependência do Paraguai em relação à Argentina. Mas apesar das boas relaçóes, havia um impasse, o "caso Sete Quedas".

Diferentemente do período em que João Goulart estava na presidência até sofrer um golpe de Estado em 1964, as divergências brasileiro-paraguaias a respeito de Sete Quedas tiveram pouca repercussão na imprensa de ambos os países. Porém, a partir da ocupação militar brasileira em Porto Coronel Renato, a área em litígio, o assunto ganhou repercussão em ambos os países, mas com maior dimensão no Paraguai.

O Paraguai estava sob uma ditadura militar em meados nos anos de 1960 e o controle sobre a imprensa, por meio da censura, evitava uma manifestaçáo crítica ao governo Stroessner por meio dos periódicos mais acessados do país. Com isso, membros oposicionistas exilados na Argentina e no Uruguai faziam suas críticas por meio de setores da imprensa destes países acusando Stroessner de ser "conivente" com os interesses brasileiros em Sete Quedas, pois “existia um plano de Stroessner juntamente com o governo brasileiro" para evitar que o chefe de Estado guarani deixasse o poder "ensejando logo a sua reeleição" através de uma reforma constitucional (FOLHA DE SÃO PAULO, 1966).

Mas a situação mudou a partir da nota de resposta do governo brasileiro, em outubro de 1965, quando este afirmou que náo retiraria os militares de Porto Coronel Renato e alegando que a referida regiáo era de soberania do Brasil. Levando em consideraçáo que naquele momento já existiam dados que revelavam o potencial hidro-energético do curso naquela fronteira e as vantagens econômicas de um futuro empreendimento, membros oposicionistas perceberam que a o "caso Sete Quedas" não deveria mais ser tratado como objeto político-partidário, mas sim, como de relevância nacional. O líder do Partido Democrata Cristáo e oposicionista declarado do governo Stroessner, Trala Flurgos, em visita à capital venezuelana, Caracas, declarou que "seu povo, não obstante as profundas divergências internas, está unido na reclamação de seu patrimônio nacional". E ainda “observou que os Saltos Del Guairá (Sete Quedas) têm um grande valor estratégico com possibilidade para ser uma usina hidrelétrica entre as maiores do mundo, com o aproveitamento de mais de 20 milhóes de kW." (ÚLTIMA HORA, 1966a)

No final de 1965, o governo paraguaio enviou outra nota ao governo brasileiro contestando os argumentos para que houvesse a ocupação de militares em Porto Coronel Renato. Em março de 1966, o Estado brasileiro reafirmou seu argumento numa nota 
de resposta, assinada pelo chanceler Juracy Magalháes, negando-se a discutir com os paraguaios a soberania de Sete Quedas, "uma vez que a fronteira entre os dois países ficou integralmente definida nos Tratados de 1872 e 1927, e perfeitamente demarcada". Acrescentou que o governo brasileiro não aceitava as acusaçôes do Estado paraguaio, o qual alegava a demarcação da regiáo em questão "insuficiente mesmo com a assinatura dos tratados de 1872 e 1927." (ÚLTIMA HORA, 1966b) Como consequência, por meio de um discurso no parlamento paraguaio, o chanceler brasileiro mencionou que aceitava a proposta brasileira, feita em dezembro de 1965, de levar o litígio fronteiriço para uma arbitragem internacional.

Os estudos possibilitam interpretar que Stroessner soube tirar proveito do litígio fronteiriço para reforçar sua imagem perante a populaçáo paraguaia. Isto porque, apesar da situação inicialmente parecer desvantajosa para o governo e servir de munição para seus oposicionistas, que incluía ex-colorados exilados, as manifestaçôes de diversos setores da sociedade, como a Federação Universitária do Paraguai e a Federaçáo dos Estudantes Secundários, que pediram a retirada da Missão Militar Brasileira de Instrução e da embaixada do Brasil de Assunção como retaliação, (LA TRIBUNA, 1965) possibilitaram um ambiente para o governo se fazer como "necessário" para os interesses nacionais. E é possível perceber tal apoio conquistado por meio de alguns dos periódicos de maior abrangência no Paraguai. Foi o caso do La Tribuna que, entre março e junho de 1966, associava a missão dos membros do Estado paraguaio no "caso Sete Quedas" aos heróis da chamada "Epopeia Nacional", a Guerra da Tríplice Aliança (1864-1870), incluindo Solano Lopez, em diversos editoriais. E, além disso, tal periódico foi um dos que mais transcrevia as publicaçóes nos jornais brasileiros referentes ao caso para situar o leitor de como o assunto era tratado na imprensa jornalística do Brasil (BARROS, 2013).

Uma das notícias no Brasil que "incendiaram" o litígio fronteiriço em solo paraguaio, foi quando o chanceler Juracy Magalhães proferiu um discurso na Comissão de Relações Exteriores do Congresso Brasileiro, alegando que o governo paraguaio estava utilizando o "caso Sete Quedas" para "desviar" a atenção da sociedade paraguaia para questôes internas. Não demorou para o chanceler paraguaio Sapeña Pastor declarar que "é incrível que o senhor Juracy Magalhães tenha atribuído a origem da questão a muitas coisas locais internas do Paraguai”. E ainda, utilizou a própria arma apontada pelo chanceler brasileiro para passar a impressáo de que era o regime militar brasileiro quem precisava desviar o foco das questóes internas ao mencionar que "toda a América conhece muito bem a situaçáo dos dois governos e sabe qual deles pode necessitar de motivos artificiais". Sapeńa Pastor disse ainda que o governo paraguaio não "tinha um relatório oficial a respeito, mas que se fossem exatas as versōes divulgadas pelas agências noticiosas, é indubitável que o Senado brasileiro náo foi informado de forma veraz e correta". O chanceler paraguaio nesta mesma declaração acusou o Brasil de estar "agredindo o Paraguai". Sendo assim, é perceptível a preocupação no noticiário paraguaio de demonstrar ao leitor que a "verdadeira" ditadura militar estava ocorrendo no Brasil e não em solo guarani.

Mas o periódico paraguaio que mais explorou o tema a favor da imagem do governo foi o Pátria, a imprensa escrita oficial do Partido Colorado. O referido jornal noticiava 
e valorizava as ações do governo no aspecto geral e reforçava os "valores democráticos" existentes no Paraguai naquele momento, como a realização de eleiçóes presidenciais, a participação de movimentos estudantis e membros de diversos sindicatos filiados ao partido nas discussóes em "prol do país", e a luta contra o comunismo entendido como "ameaça à democracia”. Os acordos diplomáticos e avanços nas negociaçóes com os dois grandes vizinhos, Brasil e Argentina, eram enfatizados como grandes conquistas tendo como exemplo a inauguração da Ponte da Amizade, em março de 1965, possibilitando a conexão do país aos portos brasileiros, além do financiamento concedido pelo Brasil nas áreas rodoviárias do Paraguai.

Suas capas continham o slogan "Vocero de la junta de Gobierno del Partido Colorado" e no decorrer do primeiro semestre de 1966 dedicou um editorial intitulado "Sobre el Salto del Guairá. Al Oído de América" (PÁTRIA, 1966a) assinado por Leopoldo Ramos Gimenez, um dos colunistas do jornal. Pelo título percebe-se a valorização do impasse com o Brasil ao ponto de chamar a atenção do leitor paraguaio de que a América estava atenta sobre tudo que estivesse relacionado à questão Sete Quedas envolvendo o Paraguai. Um editorial que possibilita também apontar que Stroessner tentava transparecer a ideia de estar prestando contas à população num tema de grande interesse nacional. E é nítida a tentativa constante das ediçóes de contagiar o leitor ao representar Sete Quedas como um território a ser defendido pelo Paraguai, sendo o governo um instrumento fundamental para conquistar a soberania daquela regiáo. Um discurso que naturalmente intencionava não apenas valorizar o regime, mas também desviar o olhar de problemas sociais, econômicos e, sobretudo, políticos vivenciados internamente. Geralmente o editorial fundamentava o argumento paraguaio sobre o litígio fronteiriço, como a exposição de mapas, e criticando a ocupaçáo militar brasileira em Porto Coronel Renato.

Os trabalhos das autoridades paraguaias para defender os "interesses nacionais", desde os estudos históricos a respeito daquela fronteira, passando pela elaboração das notas enviadas ao Brasil, até as manifestaçóes de apoio de setores da sociedade e de membros oposicionistas a favor do governo no "caso Sete Quedas" mereceram atenção frequente nas páginas do Pátria no primeiro semestre de 1966. Além disso, também enfatizava o potencial econômico da região em questão com capacidade de atingir os maiores índices internacionais de geraçáo de energia, fazendo o Paraguai ganhar destaque mundial por conta disto. Foi publicada em maio de 1966 a declaração de Júlio César Chaves, um dos membros da Comissão Assessora de Limites do Paraguai, de que Sete Quedas era também importante por causa de sua capacidade de produzir a maior geraçáo de energia no mundo, suprindo consideravelmente as necessidades do Paraguai e regióes mais desenvolvidas economicamente do Brasil, além da possibilidade de vender parte da produção gerada à Argentina, Bolívia e Uruguai (PÁTRIA, 1966b).

No “Caso Sete Quedas”, foi possível perceber que a repercussão do tema foi muito mais abrangente no Paraguai do que no Brasil muito provavelmente pelo interesse político do governo Stroessner na questáo e pelas manifestaçóes de repúdio em solo guarani, levando em conta a situação econômica e estrutural do país, sendo mediterrâneo e dependente de Brasil e Argentina. Além disso havia um elemento simbólico já mencionado 
anteriormente, o centenário da "Epopeia Nacional”, a Guerra da Tríplice Aliança, envolvendo a imagem do Brasil no país.

Em solo brasileiro a repercussão do litígio fronteiriço foi mais ampla no primeiro semestre de 1966. Os estudos permitem apontar que desde 1962, quando o Estado paraguaio questionou os estudos brasileiros para o potencial hidroenergético da fronteira em questão, o Itamaraty evitou dar maior publicidade ao assunto por entender, muito provavelmente, ser um segredo de Estado e evitar maiores problemas na geopolítica do país não apenas em relação ao Paraguai, mas também na conjuntura da América do Sul. Mas o interesse da imprensa brasileira aumentou com a repercussão do "caso Sete Quedas" no Paraguai por causa da ocupação em Porto Coronel Renato, e principalmente, após a tensão gerada na diplomacia dos dois países com as declaraçóes feitas pelo chanceler Juracy Magalhães de que o governo Stroessner fazia do litígio fronteiriço um meio de desviar a atenção para questóes internas que logo foi retrucada por Sapeña Pastor conforme mencionado nos parágrafos anteriores.

Dentre os jornais brasileiros de grande circulação que apoiavam o golpe militar de 1964, como por exemplo o Folha de São Paulo, houve a publicação de uma coluna escrita por Sérgio Paulo Freddi. Na ocasião o autor aponta que os protestos no Paraguai eram "influenciados" pelo governo ditatorial de Stroessner "mantendo a todo custo a tensão, justificando-se assim a suposição de que há outros interesses em jogo, sendo o problema da fronteira simples pretexto". Acrescentou que o Itamaraty atuava no caso "com extrema cautela, tentando manter os laços de amizade" do país com a nação guarani fazendo "a oferta de dividir com o Paraguai os benefícios do aproveitamento hídrico da região de Sete Quedas”. Afirmou ainda que o Brasil estava sendo "acusado injustamente" e esperava uma resposta positiva do governo Stroessner aceitando a proposta brasileira (FOLHA DE SÃO PAULO, 1966). No caso do jornal $O$ Globo, que também apoiou o golpe militar no Brasil, na publicaçáo da coluna intitulada "Hostilidade Injustificável," o periódico brasileiro censurou os motivos das reclamaçóes paraguaias, apenas informando que "injustamente" estudantes paraguaios depredaram a Missão Cultural e Comercial do Brasil em Assunção (PEREIRA, 1974).

Mas um periódico declarado de oposição ao regime militar brasileiro utilizou o "caso Sete Quedas” como mais um elemento para criticar o governo. O Última Hora, manifestou, por meio de uma coluna de Miguel Neiva, que o litígio fronteiriço poderia "agravar as relaçóes com o Paraguai, aumentando as tensóes diplomáticas na América do Sul." E ainda questionou se os deputados oposicionistas filiados ao MDB (Movimento Democrático Brasileiro) que apoiaram publicamente a atitude do governo brasileiro no impasse por defender os interesses nacionais, não haviam percebido isto. (ÚLTIMA HORA, 1966c) Tal publicação foi interpretada como positiva pela embaixada paraguaia no Rio de Janeiro, que enviou um documento ao governo Stroessner contendo o referido artigo em anexo para demonstrar que no Brasil havia divergências de opinióes na imprensa sobre a atitude do governo brasileiro de ocupar Porto Coronel Renato. (PARAGUAI, 1966b). Aliás, o referido artigo foi mencionado em periódicos paraguaios como o Pátria e o La Tribuna possivelmente para transmitir ao leitor tal situação. (LA TRIBUNA, 1966; PÁTRIA, 1966.) 
O Última Hora também aproveitou a oportunidade para criticar o governo brasileiro por não dar maiores informaçóes detalhadas a respeito da polêmica com o Paraguai. Em novembro de 1965, Golbery Couto e Silva, criador e chefe do Sistema Nacional de Informaçóes (SNI) e um dos estudiosos mais importantes da geopolítica brasileira na época, foi enviado para Assunção para tratar diretamente com Stroessner a respeito do litígio fronteiriço. Em um pequeno trecho, o periódico carioca questionou qual seria a razáo de Golbery visitar o governo de Stroessner e supôs que a viagem teria como principal objetivo a polêmica sobre Sete Quedas. Para o jornal, o governo brasileiro tinha a obrigação de informar à população quais eram os principais motivos do encontro de Golbery com as autoridades do Paraguai (ÚLTIMA HORA, 1965). ${ }^{4}$

E se no Paraguai houve um momento em que oposicionistas a Stroessner aproveitaram o litígio para intensificar as críticas ao governo, no Brasil isto também ocorreu. $\mathrm{O}$ jornalista e político Carlos Lacerda, conhecido por ser uma verdadeira "pedra no sapato" de presidentes brasileiros, como nos casos de Getúlio Vargas e Juscelino Kubitschek, constantemente fazia críticas ao regime militar que tanto apoiara no golpe que derrubou João Goulart, pois percebeu que a meta de ser o chefe de Estado do país estava cada vez mais distante de acontecer. Lacerda aproveitou o momento de crise entre Brasil e Paraguai para publicar um artigo com a seguinte pergunta: “afinal qual é o problema com o Paraguai?". Escreveu que o litígio fronteiriço deveria ser divulgado amplamente no Brasil para que o povo brasileiro tivesse um conhecimento profundo sobre o impasse com os paraguaios e questionou quem permitiu ao então governo brasileiro, depois de cem anos, declarar uma “segunda guerra contra o Paraguai?”(MENEZES, 1987, p. 83). Se Lacerda tratou deste assunto por oportunismo ou por acreditar que o tema era de grande relevância para o Brasil, o fato é que sua fama no cenário nacional contribuiu para que o "caso Sete Quedas" fosse mais conhecido pelo público brasileiro.

Diante de toda essa repercussão em ambas as naçóes, naquele momento a situação do impasse diplomático era o seguinte: se antes do golpe militar jornais brasileiros publicaram a informação de que João Goulart e Stroessner tinham se encontrado e anunciado que ambos os países usufruiriam em conjunto do potencial hidroenergético das Sete Quedas, desde a ocupação militar brasileira em Porto Coronel Renato aquelas supostas intençóes poderiam estar ameaçadas (MENEZES, 1987, p. 88) Com isso, a política externa brasileira colocava em risco não apenas todas as conquistas de aproximação com o Paraguai, como também possibilitava discussões no cenário sul-americano sobre a desconfiança no histórico processo de caracterização fronteiriça do Brasil. Esta preocupação, publicada

4 Os estudos realizados apontam que a atuação de Golbery Couto e Silva para tentar resolver a questão Sete Quedas com o governo paraguaio náo teve sucesso. Documentos revelam que este se encontrou duas vezes com Stroessner e também com Conselho Nacional Assessor de Limites do Paraguai para tentar resolver o impasse sobre a região de Sete Quedas, além de ter entregue ao presidente paraguaio uma carta do presidente Castelo Branco. Na ocasião, o Estado brasileiro mantinha seu posicionamento sobre a soberania de Sete Quedas. Golbery sugeriu que o governo paraguaio deveria aceitar a oferta de aproveitamento hidroenergético em conjunto "sem reclamaçáo". Segundo Menezes (1987), a atitude foi interpretada como "arrogante" pelas autoridades paraguaias e intensificou a polêmica. De certa forma, a participação de Golbery Couto e Silva demonstra a importância dada ao "caso Sete Quedas" pelo regime militar brasileiro pelo cargo que ele ocupava e pelo conhecimento adquirido em geopolítica materializado em trabalhos publicados. 
na Folha de São Paulo, foi exposta pelo chefe do Serviço de Fronteira do Itamaraty, João Guimarães Rosa (também conhecido por ser um dos maiores nomes da literatura brasileira do século XX), em uma sessão secreta da Comissão de Relaçóes Exteriores da Câmara. Segundo Rosa, "o atendimento da reivindicação paraguaia importaria na criação de precedente capaz de estimular reclamaçóes análogas de outros países". (FOLHA DE SÃO PAULO, p. 6,1966) Ou seja, a publicidade desta informação revelava o interesse em deixar o leitor situado de um assunto que era de interesse nacional.

Declaraçóes como esta sempre eram acompanhadas pelo governo paraguaio, por meio de sua embaixada no Rio de Janeiro, que enviava para Assunção recortes de jornais que tratavam do assunto no Brasil. Um destes foi a publicidade sobre a opiniáo semelhante à de Guimaráes Rosa expressada pelo diplomata e entấo deputado pelo estado da Guanabara, Afonso Arinos Filho, na Câmara dos Deputados em 23 de abril de 1966. Este teria apontado que o governo brasileiro deveria manter a firme atitude de não abrir mão de sua soberania em Sete Quedas para também evitar que países vizinhos como a Bolívia reivindicasse direitos sobre o Acre, e a Argentina na região de Palmas. Tal declaração foi expressada pela embaixada paraguaia no Brasil em nota enviada ao governo de seu país. (PARAGUAI, ???)

Em junho de 1966, o governo argentino convocou os países da Bacia do Prata (Brasil, Argentina, Paraguai, Bolívia e Uruguai) para uma reuniáo a ser realizada em Buenos Aires a fim de tratar de interesses em comum no aproveitamento das águas da bacia platina. O Estado argentino tinha interesse direto no "caso Sete Quedas" porque a proposta para o aproveitamento conjunto do potencial hirdroenergético do Rio Paraná afetariam seus projetos de construção de hidrelétricas no mesmo rio por estar a jusante de Sete Quedas. Naquele momento já estavam em discussão com o Estado paraguaio as possibilidades de aproveitamento hidroenergético conjunto por meio da usina de Corpus. Por ser geograficamente um país com poucos recursos hídricos e por ter grande demanda energética para impulsionar sua economia, a Argentina tinha no Rio Paraná um elemento em potencial para atingir parte deste objetivo e, por isso, Buenos Aires entendia que uma futura usina binacional brasileiro-paraguaia seria prejudicial. Segundo Amaral e Silva, é muito provável que tal situaçáo serviu de catalizador para que a diplomacia de Brasil e Paraguai buscassem rapidamente resolver o litígio fronteiriço para não sofrer interferência da Argentina.

As negociaçóes diplomáticas para o encontro de chanceleres ocorreram nas semanas seguintes. O periódico La Tribuna divulgou o comunicado oficial entregue no dia 10 de junho pelo governo paraguaio à imprensa local de que os governos dos dois países autorizaram as chancelarias a se encontrarem nas cidades fronteiriças de Foz do Iguaçu e Porto Presidente Stroessner para tentar resolver o problema diplomático vivenciado entre ambos sobre a questão Sete Quedas, além de tratarem de outros assuntos de grande interesse. (LA TRIBUNA, p. 3, 1966b) No dia 14, Juracy Magalháes confirmou a sua presença na reuniáo e disse que estaria indo "desprevenido e levando sugestôes que possam tirar o Brasil e o Paraguai do desagradável impasse em que se acham suas relaçóes". Comentou que ao se encontrar com Sapeña Pastor pretendia "o mesmo propósito de buscar uma solução alta, que resguarde os legítimos interesses de ambas as partes e propicie a retomada 
de relaçôes fraternais entre os dois governos e os dois povos, nos níveis em que sempre mantiveram". E sobre o estado de ânimo para o encontro, afirmou "não ser nem otimista e nem pessimista”. Finalizou a entrevista esperando que ao final do encontro ambos possam "chegar a uma conclusão feliz através de um diálogo franco entre dois homens com experiência política e experiência de vida, sabendo cada qual a imensa responsabilidade que lhe cabe".(ÚLTIMA HORA, p. 3, 1966c) Se a expectativa de Juracy Magalhães era conquistar resultados positivos naquele encontro, provavelmente Sapeña Pastor também esperava o mesmo.

Os encontros ocorreram nos dias 21 e 22 de junho de 1966, nas cidades de Foz do Iguaçu e Puerto Presidente Stroessner (atual Ciudad del Este). O teor das conversas foi entendido como secreto pela imprensa brasileira e paraguaia e foi capa das manchetes dos jornais de maior circulação nos dois países. Durante o encontro de chanceleres, alguns periódicos paraguaios opinavam que as negociaçóes seriam bem sucedidas. $\mathrm{O}$ jornal colorado Pátria publicou a informação de que os jornalistas que estavam presentes em Porto Presidente Stroessner acreditavam que o resultado da reunião seria a retirada dos militares brasileiros da área em litígio e que apenas a Comissão Mista de Fronteira brasileiro-paraguaia teria acesso à regiáo para dar continuidade aos trabalhos de demarcação. (PÁTRIA, 1966c) Já o La Tribuna mencionou que as negociaçóes lideradas pelos chanceleres demonstravam um "otimismo discreto" por conta da reunião ter sido privada, sem ter maiores esclarecimentos. (LA TRIBUNA, p. 1, 1966c) Ao analisar as informaçóes publicadas, percebe-se que os dois dias do encontro foram intensos ao ponto das reunióes dos dias 21 e 22 de junho terem ocorrido nos períodos matutino, vespertino e até mesmo noturno, (LA TRIBUNA, op. cit.) demonstrando que os governos dos dois países fariam o possível para resolver o impasse diplomático naquele encontro.

Finalmente, no dia 23 de junho de 1966, foi divulgado para a imprensa de ambas as naçóes, com consequente repercussão internacional, que o "caso Sete Quedas" estava solucionado. E desta vez, um documento havia sido assinado para formalizar o fim do impasse. Tratava-se da Ata das Cataratas, ou Ata do Iguaçu, que se tornou um marco nas relaçóes diplomáticas entre Brasil e Paraguai. Segundo Menezes:

Aquela reaproximação era táo importante para Stroessner que uma fonte de informaçáo disse que ele, incógnito, era o hóspede do apartamento 222 do hotel Acaray em Puerto Presidente Stroessner e que as frequentes interrupçôes, por parte de Sapeña Pastor, durante as conversaçôes, eram para que o chanceler paraguaio fosse consultar o homem forte do Paraguai. Verdade ou não, aquela reunificação era muito importante para o governo de Stroessner (MENEZES, 1987, p. 90).

Em resumo, a Ata das Cataratas determinava: a amizade entre os dois países; a necessidade de resolver os problemas em comum; ao "estudo e levantamento das possibilidades econômicas, em particular os recursos hidráulicos pertencentes em condomínio aos dois países do Salto Grande de Sete Quedas ou Salto de Guaíra”; a divisão igualitária da energia produzida e a aquisição da mesma a um "preço justo"; e a participação no encontro de chanceleres da Bacia do Prata em Buenos Aires, após convocação argentina. Segundo Esposito Neto, "não existe, no corpo do texto, nenhuma referência à soberania 
de Sete Quedas e à retirada das tropas militares, instaladas na região de Porto Coronel Renato" (ESPOSITO NETO, 2012, p. 141). Porém, para o mesmo autor:

o reconhecimento do condomínio das águas do Rio Paraná foi certamente uma vitória paraguaia, pois a posição anterior reconhecia o Salto de Sete Quedas integramente em território brasil eiro, e oferecia ao Paraguai um papel de sócio menor na exploração das cataratas" (2012, p. 142).

$\mathrm{Na}$ imprensa paraguaia, muitos periódicos publicaram artigos elogiando a atitude do governo Stroessner durante o encontro com a chancelaria brasileira. A possibilidade de uma visita de Juracy Magalhães à capital paraguaia também ganhou destaque nos noticiários guaranis. (BRASIL, 1966c.) Como já foi mencionado nos parágrafos anteriores, durante o encontro entre os chanceleres dos dois países a imprensa paraguaia já noticiava com otimismo a possível retirada dos militares brasileiros de Porto Coronel Renato. A embaixada brasileira em Assunção informava ao Itamaraty estas publicações. (BRASIL, 1966b) Com isso, o ambiente interno no Paraguai começava a preparar terreno para os noticiários sobre a Ata das Cataratas. Foi o caso do periódico colorado Pátria, que enalteceu os trabalhos da diplomacia paraguaia e chegou até homenagear as chancelarias dos dois países em seu editorial diário dedicado à questáo Sete Quedas. (PÁTRIA, 1966d) O La Tribuna também fez elogios às diplomacias de Brasil e Paraguai destacando em forma de manchete que "Culminaron con positivo y elocuente resultado tratativas de cancilleres de Paraguay y Brasil”. (LA TRIBUNA, p. 1, 1966d)

No Brasil, alguns periódicos como o Jornal da Tarde e o Estado de São Paulo chamaram o resultado do encontro entre Juracy Magalhães e Sapeña Pastor de "vitória da diplomacia brasileira". Nas palavras de Menezes, "é difícil dizer qual lado teve uma vitória. Talvez fosse melhor dizer que ambos, tendo em vista seus interesses econômicos e políticos, tinham sido vitoriosos" (MENEZES, 1987, p. 92).

O mesmo periódico O Jornal, que fazia parte do grupo Diários Associados, então pertencente a Assis Chateaubriand, publicou um artigo intitulado "As oito quedas do Itamaraty" tratando sobre o desfecho do "caso Sete Quedas". A publicação foi escrita por Theophilo de Andrade que criticou o governo brasileiro Para este, a Ata das Cataratas foi uma derrota para o Brasil, pois concedeu "ao Paraguai, de graça, metade da força que um dia vier a ser aproveitada na cachoeira de Sete Quedas". ${ }^{5}$ Nos últimos parágrafos do artigo, escreveu o que provavelmente muitos brasileiros pensavam sobre a solução do impasse naquela época.

Mas mesmo num país em processo de consolidação de uma ditadura, no qual alguns periódicos declaravam-se publicamente contrários aos militares, houve aqueles que consideram o desfecho do "caso Sete Quedas", uma decisão acertada mesmo sendo oposicionistas. O periódico Última Hora, através de um artigo escrito por Danton Jobim (que criou a primeira escola de Jornalismo no Rio de Janeiro), demonstrou alívio com a assinatura da Ata das Cataratas:

5 Recorte anexado ao ofício da embaixada paraguaia no Brasil enviado ao Ministério de Relaçóes Exteriores do Paraguai de 22 de julho de $1966-$ M.R.E- n. ${ }^{\circ}$ 61/66. 
Não simpatizamos com o modo por que o governo da revolução vem tratando certas questóes de nossa política externa. Se evitamos fazer comentários a respeito é porque o problema interno brasileiro, que é a redemocratização do país, está para nós acima de qualquer outro.

No caso recente com o Paraguai, preferimos calar, para que não dissesse que a imprensa oposicionista leva a sua intransigência ao ponto de tentar agravar conflitos entre o Brasil e seus vizinhos.

Pelo contrário, sempre receamos esse agravamento, sobretudo em face de certas declaraçóes pouco diplomáticas de nossas autoridades. Reconhecemos agora que, nas negociaçóes da Foz do Iguaçu, se deu um valioso passo para o esvaziamento da questáo de limites com o Paraguai, que só tendia a envenenar-se. Foi um alívio! [...]

A fórmula encontrada parece-nos justa. Demonstramos com ela ao Paraguai que não queremos espoliá-lo de uma riqueza incalculável. E ainda mais: ao adotar essa fórmula, náo espoliamos o Paraguai e não abrimos mão de nossa soberania territorial na região, o que é muito importante.

A oposição, que já demonstrou não fazer política interna à custa dos interesses brasileiros, deve regozijar-se com o resultado obtido, ou pelo menos sentir-se aliviada. (ÚLTIMA HORA, p. $2,1966 \mathrm{~d})$

E se no Brasil houve divergências de opiniáo publicadas em periódicos sobre o desfecho do "caso Sete Quedas", o mesmo ocorreu de forma limitada no Paraguai. Segundo informaçóes que constam em documento diplomático, o jornal El Enano de Assunção apontou em um artigo intitulado "Humillados ante Brasil" que o governo paraguaio havia cedido às pressões do Estado brasileiro assinando a Ata das Cataratas. Isto demonstra que o fim do impasse também serviu de muniçáo para atacar o governo Stroessner de um ângulo contrário àqueles que aplaudiram em solo guarani a assinatura da Ata. Porém, o colorado Pátria logo criticou o artigo publicado pelo El Enano. A embaixada brasileira em Assunção enviou ao Itamaraty recorte da crítica feita pelo Pátria. (BRASIL, 1966b) ${ }^{6}$

É possível perceber até aqui como o assunto foi repercutido na imprensa de ambos os países e as diferentes opinióes expressas numa conjuntura de ditadura militar no Brasil e Paraguai, ainda que limitada pela censura, mesmo quando houve repúdio a conduçáo de seus respectivos governos no "caso Sete Quedas" e seu desfecho com a assinatura da Ata das Cataratas. O acordo possibilitou que os dois países desenvolvessem nos anos seguintes intensos estudos em conjunto para o aproveitamento hidroenergético do curso médio do Rio Paraná, por meio da formação de uma Comissão Mista Técnica, em 1967, com auxílio de suas diplomacias. O resultado seria a assinatura do Tratado de Itaipu, em abril de 1973, o maior acordo diplomático brasileiro-paraguaio da história, e daria início à construção da maior usina hidrelétrica do mundo até poucos anos atrás.

6 É preciso informar ao leitor que no referido documento citado não constam os argumentos tratados nem do periódico El Enano e nem do Pátria. 


\section{CONSIDERAÇÕES FINAIS}

O impasse entre Brasil e Paraguai a respeito de Sete Quedas foi um dos episódios mais polêmicos nas relaçóes entre ambos no século XX. Diante da conjuntura interna nos dois países, sob regimes ditatoriais, a imprensa foi utilizada como instrumento para divulgar a defesa dos interesses nacionais que estavam em jogo, principalmente no Paraguai. A habilidade da diplomacia paraguaia nas relaçôes com o Brasil que culminaram com a Ata das Cataratas possibilitaram reforçar a propaganda do governo Stroessner de defensor dos interesses do Paraguai fazendo uso de símbolos, mitos e heróis nacionais, que fortaleceram o movimento em defesa da regiáo de Sete Quedas. Apesar de terem surgido críticas, ainda que em menor proporção por causa do rígido controle ditatorial no Paraguai, a imprensa foi um importante instrumento para Stroessner reforçar publicamente a importância da aproximaçáo geopolítica com o Brasil, ao mesmo tempo que, ao contrário do que apontavam seus opositores, seu governo não era submisso ao Estado brasileiro. Já no Brasil, o "caso Sete Quedas" teve menor destaque na imprensa do que no Paraguai. E dentre os periódicos pesquisados o Última Hora, um dos jornais de oposiçáa ao governo Castelo Branco, foi o mais crítico em relaçáo ao Estado brasileiro no episódio criticando a ocupação militar em Porto Coronel Renato. Já jornais que apoiaram o golpe militar de 1964, como Folha de São Paulo e $O$ Globo, não fizeram críticas ao governo e acusaram a ditadura paraguaia de incendiar a discussão.

Sendo assim, percebemos que o "caso Sete Quedas" foi um tema explorado na grande imprensa dos dois países de acordo com seus posicionamentos políticos na conjuntura em que se encontravam. O que reforça o papel dos periódicos, tanto como instrumentos de propaganda dos regimes ditatoriais quanto veículos de críticas aos mesmos. O tema estudado demonstra a importância permanente sobre a imprensa por esta emitir opiniốes afirmando que a sua função é tratar dos "fatos", ao mesmo tempo defendendo um projeto político. Por isso, a sua utilizaçáo como fonte na temática tratada neste artigo é um exemplo de como periódicos também podem ser explorados por pesquisadores das Relaçôes Internacionais para compreender a interpretaçáo da política externa de um país internamente de acordo com os interesses políticos e econômicos que estấo em jogo. 


\section{FONTES}

Acervo digital da FOLHA DE SÃO PAULO

Disponível em: http://acervo.folha.com.br/

Acervo digital do ÚLTIMA HORA

Disponível em: http://www.arquivoestado.sp.gov.br/uhdigital/pesquisa.php Arquivo do Edifício da Vice-Presidência do Paraguai em Assunção

Biblioteca Nacional de Assunção

- Jornal LA TRIBUNA

- Jornal PÁTRIA

Centro de Documentação do Ministério de Relações Exteriores em Brasília-DF 


\section{REFERÊNCIAS BIBLIOGRÁFICAS}

AMARAL E SILVA, Ronaldo Alexandre do. Brasil-Paraguai: marcos da política pragmática na reaproximação bilateral, 1954-1973. Um estudo obre o papel de Stroessner e a importância de Itaipu. INFORMAR ANO DE DEFESA, NÚMERO DE FOLHAS. Dissertação (Mestrado em Relações Internacionais). IREL/UNB, Brasília,, 2006.

BARROS, Luiz Eduardo Pinto . Os Saltos da Discórdia: o impasse entre Brasil e Paraguai em torno das Sete Quedas (1962-1966). Saarbrücken, Alemanha: Novas Ediçóes Acadêmicas, 2013. v. 1.212 p.

BETIOL, Laércio. Itaipu - Modelo Avançado de cooperaçáo internacional na Bacia do Prata. Rio de Janeiro: FGV, 1983.

BRASIL. Ofício de 29 de outubro de 1965 - C.D.O. n. ${ }^{\circ}$ 310. (Da embaixada brasileira em Assunção para o Ministério de Relaçóes Exteriores do Paraguai).

. Ofício da Embaixada brasileira em Assunção para o Itamaraty de 11 de março de 1963- n. ${ }^{\circ} 122 / 650.4(04)$.

. Ofício do Itamaraty de 22 de junho de 1966- CDO n.o 930.1 (42)(43) 1966a.

. Ofício do Itamaraty de 23 de junho de 1966 n..$^{\circ} 4561930.2(42)(43) .1966$ b.

. Ofício do Itamaraty de 24 de junho de 1966 n.o 469\430.1(42)(43). 1966c.

BRASIL Diz ao Paraguai que não Aceita Debater as Fronteiras de Sete Quedas. Última Hora, Rio de Janeiro, 1966, v. 3, n. 6, p. 3, 26 mar.1966.

BRASIL É Alvo de Protestos no Paraguai. Folha de São Paulo, São Paulo, p. 2, 7. abr. 1966.

CANCÍlLERIAS Acertan Encuentro. La Tribuna, Assunção, p. 3, 11 jun. 1966 b.

CAUBET, Christian Guy. As grandes manobras de Itaipu: energia, diplomacia e direito na Bacia do Prata. São Paulo- Christian Guy Caubet. Academia, 1989.

CARDOSO, Efraím. Breve historia del Paraguay. Asunción: Servilibro, 2007.

CRITICAS en Brasil por Ocupación en Salto del Guairá. La Tribuna, Assunção, p. 3, 1. jun. 1966a.

CULMINARON com Positivo Y Elocuente Resultado Tratativas de Cancilleres de Paraguay Y Brasil. La Tribuna, Assunção, p. 1, 24 jun. 1966d.

ARCE, Omar Díaz de. El Paraguay contemporáneo (1925-1975). In: CAZANOVA, Pablo González (Coord.). América Latina: história de medio siglo. 8. ed. México : Siglo Veintiuno, 1991.

DORATIOTO, Francisco. O Brasil no Rio da Prata (1822-1994). 2. ed. Brasília: FUNAG, 2014.

ESPÓSITO NETO, Tomaz. Itaipu e as relaçóes brasleiro-paraguaias de 1962 a 1979: fronteira, energia e poder. São Paulo. Tese de doutorado pela PUC, 2012. 
FIM DA POLÊMICA COM O PARAGUAI. Última Hora, Rio de Janeiro, p. 2, 25 jun. 1966 d.

GUIMARÁES ROSA Trata Sobre Impasse com o Paraguai na Câmara dos Deputados. Folha de Sáo Paulo, São Paulo, p. 6, 30 abr. 1966.

JURACY Confirma Encontro com Chanceler Paraguaio. Última Hora, p. 3, 15 jun. 1966c. LEITE, Antonio Dias. A energia do Brasil. Rio de Janeiro: Nova Fronteira, 1988.

MELLO, Leonel Itaussu Almeida. A Geopolítica do Brasil e a Bacia do Prata. Dissertação (Mestrado em sociologia política). PUC, São Paulo, 1987.

MENEZES, Alfredo de Mota. A herança de Stroessner: Brasil-Paraguai 1955-1980. Campinas: Papirus, 1987.

MORAES, Ceres. A consolidaçáo da ditadura de Stroessner (1954-1963). Dissertação (Mestrado em história). Porto Alegre, 1996.

NUEVO ENCUENTRO DE CANCILLERES. La Tribuna, p. 1, 22 de junho de 1966c.

OPOSIÇÃO PARAGUAIA Critica Brasil. Folha de Sáo Paulo, São Paulo, INFORMAR ANO DO PERIÓDICO, VOLUME, NÚMERO, p. 5, 18 abr. 1966.

OPOSICIONISTA Apoia Governo Paraguaio. Últma Hora, p. 6, 12 mar. 1966a.

PARAGUAI. Ofício do Ministério de Relaçôes Exteriores, de 13 de fev. de 1962a, M.R.P. n. 18.

. Ofício do Ministério de Relaçoes Exteriores do Paraguai n.o 94, de 12 de março de 1962b.

(Da embaixada paraguaia no Brasil para o Itamaraty).

. Ofício do Ministério de Relaçóes Exteriores do Paraguai para o Itamaraty de 20 de dezembro de 1963 - M.R.B n. ${ }^{\circ} 151$.

. Ofício do Ministério de Relaçóes Exteriores do Paraguai de 13 de setembro de 1964 M.R.P n. ${ }^{097 .}$

Ofício do Ministério de Relaçóes Exteriores do Paraguai de 01 de abril de 1966a M.R.E.P.N- 23/66.

. Ofício do Ministério de Relaçóes Exteriores do Paraguai M.R.P n. ${ }^{\circ} 62$.

. Ofício da Embaixada paraguaia no Brasil para o Ministério de Relaçóes Exteriores do Paraguai de 2 de junho de 1966b - D.P.I n. ${ }^{\circ} 154$.

PARAGUAI Responde Ao Brasil. Última Hora, Rio de Janeiro. p. 4, 26 mar. 1966b.

PEREIRA, Osny Duarte. Itaipu: prós e contras. Rio de Janeiro: Paz e Terra, 1974.

PERIODISTA BRASILEÑO Critica la Ocupación em Salto del Guairá. Pátria, Assunção, p. 4, 1 jun. 1966.

SALTO DEL GUAIRÁ. La Tribuna, p. 5, 24 nov. 1965.

SERÁ do Brasil a maior hidrelétrica do mundo, Última Hora, p.1, 21 de jan. 1964. 
SOBRE El SALTO DEL GUAIRÁ. AL OÍDO DE AMÉRICA. Pátria, Assunção, fev.jun. 1966.

Pátria, Assunção, p. 3, 21 maio 1966b.

. Pátria, Assunção, p. 3, 22. Jun. 1966c.

. Pátria, Assunçáo, p. 3, 24. Jun. 1966d.

STROESSNER é Reeleito No Paraguai. Última Hora, Rio de Janeiro, p. 6, 22 de fev. 1963.

ÚLTIMA HORA. Opiniāo De “UH”: Brasil-Paraguai. Rio de Janeiro, p. 4, 29 nov. 1965.

. Rio de Janeiro, p. 4, 30 maio 1966c.

Artigo recebido em 05/08/2017

Artigo aceito em 20/11/2017 